\title{
MATERIAL MANAGEMENT IN CONSTRUCTION - A CASE STUDY
}

\author{
T. Phani Madhavi ${ }^{1}$, Steve Varghese Mathew ${ }^{2}$, Roy Sasidharan ${ }^{3}$ \\ ${ }^{1}$ Assistant Professor, ${ }^{2,3}$ Former Graduate Student, Department of Civil Engineering, Sathyabama University, \\ Chennai, Tamil Nadu, India, talasilamadhavi@gmail.com
}

\begin{abstract}
The objective of the present study is to understand about all the problems occurring in the company because of improper application of material management. In construction project operation, often there is a project cost variance in terms of the material, equipments, manpower, subcontractor, overhead cost, and general condition. Material is the main component in construction projects. Therefore, if the material management is not properly managed it will create a project cost variance. Project cost can be controlled by taking corrective actions towards the cost variance. Therefore a methodology is used to diagnose and evaluate the procurement process involved in material management and launch a continuous improvement was developed and applied. A thorough study was carried out along with study of cases, surveys and interviews to professionals involved in this area. As a result, a methodology for diagnosis and improvement was proposed and tested in selected projects. The results obtained show that the main problem of procurement is related to schedule delays and lack of specified quality for the project. To prevent this situation it is often necessary to dedicate important resources like money, personnel, time, etc. To monitor and control the process. A great potential for improvement was detected if state of the art technologies such as, electronic mail, electronic data interchange (EDI), and analysis were applied to the procurement process. These helped to eliminate the root causes for many types of problems that were detected.
\end{abstract}

Keywords: Material Management, Construction

\section{INTRODUCTION}

Materials management is defined as a management system that is required in planning and controlling the quality \& quantity of the material, punctual equipment placement, good price and the right quantity as required. Material management is a management system that integrates purchasing, shipping and material control from suppliers. Based on those definitions, generally materials management can be defined as a process of planning, executing, and controlling the right source of materials with the exact quality, at the right time and place suitable for minimum cost construction process. Capability to coordinate and integrate purchasing, shipping and material control from suppliers is required for material cost control. Three important phases that holds the key to a successful materials management are materials purchasing, materials usage, and storage .It is used to reduce the cost, which increases profitability and streamlines the production. Apart from management of material cost and its supply it helps in its proper utilization, transportation, storage, handling and distribution. Selection of personnel for marketing, purchasing, inventory control, stores management and materials handling and their training and placement is also to be seen by the materials management department This indicates that it is very essential to have a materials management department in any organization to support the management in the production activities. It also helps in the marketing, sales promotion and control of all the types of materials for its quantity, quality and cost. Thus, the objective of this paper is to clarify the roles and possibilities of material management in construction.

The present case study was done at Raviz hills. It was noticed that the materials are improperly procured and stored and there is a lack of inventory control and improper management. The finest details of procurement process was studied and an attempt has been made to meet the effective transportation system, proper inventory control and purchase can be done with technological measures and also, determines the profit and loss that occur under particular schedule based on the purchasing and inventory stores.

\section{EXPERIMENTAL METHODOLOGIES}

The experimental analysis consists of theories and practical consideration of the concepts. Therefore, the present work was classified as follows.

2.1 Analysis of site and management

2.2 Analysis on Inventory controlling

2.3 Analysis on purchasing procedures

2.4 Analysis on Procurement and Tracking

2.5 Analysis on costs

\subsection{Analysis of Site and Management}

The analysis was done to understand what are all the problems occurring in the company because of improper application of material management. The solutions that provided in this work 
may cost a lot in the beginning, but it will help the company in the long run by providing solutions to the key problems like lack of specification, delay, improper procurement etc. According to the problems that generally occur in the site due to the improper material management, was categorised each problem and created a cause-effect diagram, where factors such as, inventory, purchase, procurement, were all generally addressed to procurement cycle. For this purpose, the study was done by visiting the site. Site survey was done, and prepared questionnaires accordingly and problems to each above mentioned groups were analysed and solutions thus were given. Substantial evidences in the form of photos were taken to analyse the procurement problems occurring in the present case study. Questions were prepared accordingly and those prepared questions were given as a challenge to the site managers, quality control inspector, project manager, purchase manager. From the questionnaires prepared and the answers thus obtained from them were categorized into each class of problems. From those classes it was understood that lack of technological implications and scientific approach were lacking with respect to the procurement process. Thus the problems were pointed out to them and they agreed to each above mentioned problems that were occurring in their site and thus corrections would be implemented by them in their next oncoming projects.

\subsection{Analysis on Inventory Controlling}

In the inventory process, the methodology adopted was preparing questionnaires and allocating marks for each, by categorizing them into each of their subsystem problems, such as supply, materials and equipments, weightages were given substantially. Then, based on this the solutions were offered in the form of cause - effect diagram and flow charts, graphs were also prepared, depicting problems such as delay, lack of specification, excess and lack of inspection.

\subsubsection{Inventory Planning}

i. Production planning requires purchase and inventory planning decisions for an organization to control expenses and finances.

ii. To get the purchase benefits, discounts, reduced transportation and ordering cost the bulk purchase may be economical. Inventory of such materials are stored for longer time.

\subsection{Analysis on Purchasing Procedures}

All the organizations need an efficient and economic purchasing and procurement of its various supplies of materials from the suppliers.

\subsubsection{Process of Purchasing}

The process of purchasing involves various steps to be followed as routine matter by the purchase department. i) Identification of materials: Identify the materials to be purchased by receiving the requisitions received from various departments.

(ii) Purchase requisitions: Purchase requisitions are documents listing the requirements of materials from the various stores written by the storekeeper received by the purchase department from various departments. The planning department for special purchases for non-stock items also prepares the purchase requisitions. The purchase requisitions are made as Bill of Materials (BOM) of a product, which specifies quantities, needed. The purchase requisitions are generally prepared in triplicate. One copy sent to the purchase department signed by the storekeeper, works manager and production controller, second copy sent to materials control or planning department and third copy is retained by the requisitioned.

\subsection{Analysis on Procurement and Tracking}

In this, the concept is based on procurement and tracking of the materials which is done with the help of RFID and bar coding scanners. In procurement tracking, the concept of tracking the material is done mainly with the help of barcode scanners, where the quality control manager can view the materials to where it is being transported. Hence a check on the materials can be done. Once the transportation has arrived at site, the material is being passed by cross checking it with the bill of quantities and bill of loading, with the consignee. Once the consignee accepts the bill of loading it is then conveyed to the consigner. The whole case study of procurement and tracking was done by us with the help of questionnaires.

\subsection{Analysis on Cost}

\subsubsection{ABC Analysis}

This is most popular inventory control technique adopted as Pareto's Law. Large amount of capital is invested in purchase of costly items in small number. Eighty percent of the cost of materials purchased is required for only Twenty percent costly items for efficient inventory control in stores where the large number of materials are to be handled, the classification of them is necessary to take particular care of costly items, which are less in number. The ABC analysis is commonly used in most of the organizations

To classify the materials according to their sales values. In this method, all the items of stores are classified in three groups as $\mathrm{A}, \mathrm{B}$ and $\mathrm{C}$ as explained below.

(i) The quantity of each item used annually multiply by its unit sales price is sales value of that item. All such sales values of all the items are calculated and tabulated.

(ii) The items, its quantity sold and sales values are tabulated in decreasing order and the sales values are added item-wise and shown in next column. 
(iii) The totals of quantity and sales values of all the items used annually are found out. The percentage sales values of each item is found out and percentage of quantity of each item is also found out. These two columns are added showing percentage of total sales values item wise and percentage of total quantity of sales.

(iv) Seventy percent of total sales value items will be listed in A category. Its percentage quantity used is found out.

(v) About $20 \%$ of total sales value items will be listed in B category. Its percentage quantity used is found out.

(vi)Balanced about $10 \%$ of total sales value items will be listed in $\mathrm{C}$ category. Its percentage quantity will be remaining balance.

\subsubsection{Characteristics of $\mathrm{ABC}$ Items}

\section{A-Items}

These items have $70 \%$ of sales value but less in quantity about 15 to $20 \%$. The capital should not be blocked in these items. They can be ordered frequently and consumed immediately. The purchase of these items will be controlled by Director and cared most in the company. They are only 10 to $15 \%$ quantitywise and require special attention in stores.

\section{B-Items}

They have about 20 to $25 \%$ sales value and same quantity to purchase. Since they are medium valued items therefore large inventory of them is not necessary. They can be ordered frequently but at the same time the quantity ordered should be such that it will be economic to purchase and its shortage should not be there. They are less valued than A items and quantity-wise about 15 to $25 \%$.

\section{C-Items}

They have the least sales cost about $10 \%$. They are required in large quantity about 50 to $60 \%$. They can be purchased in bulk to avail large discounts and fewer prices to pay. This will also reduce the cost of ordering and purchasing. They can be purchased once or twice in a year. They are least-valued items. Advantages of ABC Analysis

(i) The inventory control of different categories of items will be better if costlier items are not stored for large period, which reduces capital investment.

(ii) The quantities of various categories of items are economically ordered and stored as per need. It saves the cost of ordering and carrying the inventories.

(iii) The purchasing of various categories of items becomes easy and discounts are also obtained on large purchase of items of $\mathrm{C}$ category.

(iv)Better record keeping of different categories of items helps in good inventory control

\subsubsection{First In First Out (FIFO) Method}

In this method, the material stored first is issued first. For using this procedure, the following methods are used.

Double Area System: In this particular method, two areas are used for each item to be stored and issued. The new lots of items are stored in second empty area and materials are issued from first area where previous old lot is stored. When first area is emptied, the material from second area is shifted to first area so that second area is emptied to receive the fresh materials.

Moving Division System: In this method is the place selected for each item is more in area than required to provide space between new and old lots. The materials supplied first are placed first in right hand side area from where it is issued. The fresh lot is supplied in the second area on left hand side and shifted to right hand side when it is emptied.

Gravity Feed System: The new materials are fed at the top of the containers or piles and removed from the bottom.

\subsubsection{Benefits of the Method}

The method uses actual cost of the material for valuation and it is very easy to use. The only disadvantage of the method is that if large variation of prices is there, no consideration is given to current market prices. When the prices are falling, the material charged to production is high and when the prices are rising, the material charged to production is low and replacement cost is high.

\section{RESULTS AND DISCUSSION}

A comprehensive case study on material management at work site was done. Attempt has been made to improvise the inventory controlling measures, purchasing measures, by looking into the detailed report of previous organization hierarchy and their management. The present work comprises the redesigning of the entire organization hierarchy without touching the core competency. Management was sub divided into sub system and further task work such as purchase manager, supervisor in charge. Under them further sub divide into supervisors and helpers. Effort is taken to improvise the existing hierarchy effectively, by improving purchasing department, financial department, material management department to merge with one and each other. Microscopically, dissections was done into the matters of purchasing, transportation and introduction of new possibilities, like, purchase requisition slip, tender quotation form, technologies like RFID and PDA were also initiated to help in achieving a better procurement control at the work site. Analysis was done at the site based on cost input, such as $\mathrm{ABD}$ analysis and FIFO analysis. In ABC analysis, we categorize whole material into $\mathrm{ABC}$ type materials were $\mathrm{A}$ category consist of $10 \%$ of total material involved in 
construction but that cost $70 \%$ of the total cost. Similarly B and $\mathrm{C}$ type material were also classified accordingly by this we mean that during construction the materials can be released as per the above concept, so that, we can strengthen the financial control and proper scheduling and programming of the work can be achieved, there by graduating progress in work efficiently.

Further cost analysis was done based on FIFO input, and similarly cost controlling efficiently was achieved, that is, if a contractor quotes a rate, and later on we calculate a similar quote for the same material for what the contractor has given. We can find that there is a change in the quotation. Thus, enabling us to have a broad outlook on the financial control of the work. Thus, helping in proper release of the finance and preparation of the budget preparing process.

New technological implications like RFID, PDA, were helped in proper scheduling and financial control. Accurate data collection has always been an important part of project control both in procurement and construction phases. The Radio Frequency Identification RFID enables precise data acquisition by tracking materials. This technology enables the detection and identification of tagged objects through the data it transmits. RFID uses radio waves to identify people and objects. An RFID system consists of an RFID tag and an RFID reader. The RFID tag consists of a small microchip and an antenna. Data is stored in the tag, usually in the form of a unique serial number. The RFID reader acts as a transmitter/receiver. The reader transmits an electromagnetic field that wakes up the tag and provides the power required for the tag to operate. The tag then transfers the data to the reader through the antenna. This data is then read by the RFID reader and transferred to the Pocket PC or computer. RFID tags do not have to be line-of sight. They only have to be within the reader's radio range. This evolution in automated data acquisition has become the next paradigm in construction industry. By using software, construction site documentation can be simplified and made faster and there is increased efficiency. Therefore, there is a need of Personal Digital Assistant (PDA) to run the software to enhance the productivity of jobsite management.

\section{CONCLUSIONS}

1) In the present case study, analysis on the work site was done with the previous knowledge of the material management, and new methodologies were implemented at work site, based on the current construction scenario.

2) Following aspects were taken into consideration, the original site layout was redesigned, then the proper management was bought in and a whole new concept was derived.

3) Understanding of the problems that occur at the work site due to, inventory, purchasing and on how materials are being handled at the work site were taken into consideration. On how, materials are being procured was done with questionnaires and weight ages were given to each. On further these problems were tackled with cause effect and diagram and how materials can be properly procured with the help of proper flow charts.

4) Similarly, analysis was done on purchasing and new concept of purchase requisition slip and tender quotation were introduced.

5) Importance on how materials are properly procured at the site was also taken into consideration and new appropriate technological implications were introduced like RFID, PDA, which helped us in a proper scheduling and financial control for proper scheduling and based on the materials importance, and on how they have to be released, ABC analysis and FIFO analysis were done.

6) From the above theory and concepts, new theories which help us in proper material management at worksite were identified and prime importance was given to them. The case study as a whole was submitted to the Raviz Hills management system, and they have been agreed, and also promises were done to implement these material management strategies, within 2 to 3 years for the future projects.

\section{REFERENCES}

[1]. Bell, L. C. and Stukhart, G, "Cost and Benefits of Materials Management Systems Journal of Construction Engineering and Management, Vol. 113, No. 2, 1987,pp 222234.

[2]. Elbeltagi, E., Hegazy, T. and Eldosouky. A.,'Dynamic Layout of Construction Temporary Facilities Considering Safety", Journal of Construction Engineering and Management, Vol. 130, No. 4, 2004, pp 534-541

[3]. Formoso, C. T., Soibelman, L., De Cesare, C. and Isatto, E. L, "Material Waste in Building Industry: Main Causes and Prevention" Journal of Construction Engineering and Management. Vol. 128, No. 4, 2002,pp. 316-325. 